\title{
Change-point analysis of geophysical time-series: application to landslide displacement rate (Séchilienne rock avalanche, France)
}

\author{
D. Amorese, ${ }^{1,2}$ J.-R. Grasso, ${ }^{3}$ S. Garambois ${ }^{3}$ and M. Font ${ }^{4,5}$ \\ ${ }^{1}$ OVSG, IPGP, Sorbonne Paris Cité, UMR 7154 CNRS, France. E-mail: amorese@ipgp.fr \\ ${ }^{2}$ Department of Biology and Earth Sciences, Université de Caen-Normandie, Esplanade de la Paix, CS 14032 Caen Cedex 5, France \\ ${ }^{3}$ ISterre, Univ. Grenoble Alpes, Univ. Savoie Mont Blanc, CNRS, IRD, IFSTTAR, ISTerre, F-38000 Grenoble, France \\ ${ }^{4}$ Université de Caen, Caen, F-14000 France \\ ${ }^{5}$ CNRS, UMR 6143 M2C, Caen, F-14000 France
}

Accepted 2018 February 13. Received 2018 January 12; in original form 2017 June 17

SUMMAR Y

The rank-sum multiple change-point method is a robust statistical procedure designed to search for the optimal number and the location of change points in an arbitrary continue or discrete sequence of values. As such, this procedure can be used to analyse time-series data. Twelve years of robust data sets for the Séchilienne (French Alps) rockslide show a continuous increase in average displacement rate from 50 to $280 \mathrm{~mm}$ per month, in the 2004-2014 period, followed by a strong decrease back to $50 \mathrm{~mm}$ per month in the $2014-2015$ period. When possible kinematic phases are tentatively suggested in previous studies, its solely rely on the basis of empirical threshold values. In this paper, we analyse how the use of a statistical algorithm for change-point detection helps to better understand time phases in landslide kinematics. First, we test the efficiency of the statistical algorithm on geophysical benchmark data, these data sets (stream flows and Northern Hemisphere temperatures) being already analysed by independent statistical tools. Second, we apply the method to 12-yr daily time-series of the Séchilienne landslide, for rainfall and displacement data, from 2003 December to 2015 December, in order to quantitatively extract changes in landslide kinematics. We find two strong significant discontinuities in the weekly cumulated rainfall values: an average rainfall rate increase is resolved in 2012 April and a decrease in 2014 August. Four robust changes are highlighted in the displacement time-series (2008 May, 2009 November-December-2010 January, 2012 September and $2014 \mathrm{March}$ ), the 2010 one being preceded by a significant but weak rainfall rate increase (in 2009 November). Accordingly, we are able to quantitatively define five kinematic stages for the Séchilienne rock avalanche during this period. The synchronization between the rainfall and displacement rate, only resolved at the end of 2009 and beginning of 2010, corresponds to a remarkable change (fourfold increase in mean displacement rate) in the landslide kinematic. This suggests that an increase of the rainfall is able to drive an increase of the landslide displacement rate, but that most of the kinematics of the landslide is not directly attributable to rainfall amount. The detailed exploration of the characteristics of the five kinematic stages suggests that the weekly averaged displacement rates are more tied to the frequency or rainy days than to the rainfall rate values. These results suggest the pattern of Séchilienne rock avalanche is consistent with the previous findings that landslide kinematics is dependent upon not only rainfall but also soil moisture conditions (as known as being more strongly related to precipitation frequency than to precipitation amount). Finally, our analysis of the displacement rate time-series pinpoints a susceptibility change of slope response to rainfall, as being slower before the end of 2009 than after, respectively. The kinematic history as depicted by statistical tools opens new routes to understand the apparent complexity of Séchilienne landslide kinematic.

Key words: Creep and deformation; Europe; Geomechanics; Statistical methods; Timeseries analysis. 


\section{INTRODUCTION}

The mitigation of landslide hazard is receiving tremendous attention in many parts of the World. Two main approaches help to assess the risk: the static approach (prevention) consists in mapping of the landslide susceptibility, whereas the dynamic approach aims to predict the spatial-temporal progress of landslides through monitoring and mathematical/physical models. The role played by antecedent rainfall in the triggering of landslide is not a matter of debate (Van Asch et al. 1999; Godt et al. 2006): it prompts several authors (Ray \& Jacobs 2007; Ponziani et al. 2012; Brocca et al. 2012) to propose rainfall and soil moisture thresholds in the design of early warning system. Thus, most landslide warning systems use thresholds that are tied to recent precipitation amounts and durations. Baum \& Godt (2010) in their compilation study for precipitation thresholds across the USA reported that, at every scale (including county and nation), there is no consensus on these values: variations of several orders of magnitude are frequently observed. Our study proposes a slight different approach: we do not focus on rainfall events that resulted or did not result in landslide. Our attention is primarily focused on surface landslide displacement values (and associated rainfall series). Indeed, it has been shown that a more accurate prediction of the occurrence of failure can be obtained by measuring the landslide displacement rates than by analysing rainfall intensity-duration diagrams (Federico et al. 2004). Actually, as for rainfall, there is no consensus on velocity threshold values for alerts: for instance, for creeping-type rockslides, the critical values may differ by an order of magnitude from one site to another, from tens to several hundred $\mathrm{mm} \mathrm{d}^{-1}$ (Crosta \& Agliardi 2003). We conduct an analysis that is related to this critical issue of the definition of thresholds, but assessing the reliability of the correlation between the probability of occurrence of a landslide and rainfall measurements is not our primary objective. When a landslide is monitored, there is interest in determining whether changes in displacement measurements are the results of random chaotic processes or indicate significant and lasting changes in the underlying physics (or in the way data are collected/processed). If the change is significant, then identifying when it occurs and quantifying its significance can be important breakthroughs toward the identification of the triggering processes and the onset of possible early warning strategies. Incidentally, analysing the dynamics of landslide is a pre-requisite in the most sophisticated applications of the statistical impulse response model for the prediction of landslide velocities (Abellán et al. 2015; Bernardie et al. 2015). The analysis of the time evolution and/or the cross-correlation of measurements collected on landslides is part of the ordinary course of research on solid flow hazards (Hungr et al. 2005; Helmstetter \& Garambois 2010; Crosta et al. 2014; Rianna et al. 2014; Benoit et al. 2015; Schlögel et al. 2015; Confuorto et al. 2017). But so far, no reproducible method of analysis has been applied on these kinds of data for the determination of successional stages. In this paper, a non-parametric technique for the detection of changes in time-series, first introduced by Lanzante (1996), is applied to the time-series of the Séchilienne landslide. The purpose of this study is to improve the description of the landslide kinematics (definition of motion acceleration or deceleration stages) and then to better assess which factors (average rainfall rate, rainfall frequency and intense rainfall event) influence the Séchilienne landslide evolution. In the first part of this work, the efficiency and outcomes of the methodology are tested on natural and synthetic data sets. Then, landslide displacement and rainfall series are analysed. Eventually, this approach allows to sort out a list of features of the five kinematic stages of the Séchilienne rock avalanche in the 20032015 period.

\section{STUDY SITE AND DATA}

The Séchilienne landslide is located on the southern slope of the Mont-Sec Massif in the Dauphiné region (French Alps). The most unstable part of the landslide (estimated volume: $3 \times 10^{6} \mathrm{~m}^{3}$ ) is threatening the main communication axis between major alpine cities, Grenoble and Briançon cities, and including key access to both regional ski resorts and northern Italy region. Formation of a landslide dam lake into the downslope Romanche river valley is another possible major issue of the earthfall. The survey of the site began in 1985, including dense displacement and weather measurements. The surface strain monitoring of the Séchilienne landslide in fully operated by the CEREMA (Centre d'Etudes et d'Expertise sur les Risques, l'Environnement, la Mobilité et l'Aménagement) of Lyon (Kasperski et al. 2010). In this study, we use displacement data from the most active zone of the landslide, that is, those acquired by extensometer 13 (Fig. 1). We investigate lengthening values that have been collected every day by the extensometer 13 from 2003 December 1 to 2015 December 31 for a total of 4337 recordings. The Vizille weather station (latitude: $45.0802^{\circ} \mathrm{N}$; longitude: $5.7694^{\circ} \mathrm{E}$; elevation: $290 \mathrm{~m}$ ) maintained by Sébastien Pierart (ROMMA association) is located about $3.5 \mathrm{~km} \mathrm{NW}$ of the landslide and operated on the whole time period. It is also sampled at a daily rate. Several authors (Durville et al. 2009; Chanut et al. 2013; Vallet et al. 2013) raised the importance of the sampling rate for the analysis of the Séchilienne data. Durville et al. (2009), for example, performed analyses for annual, monthly, $10 \mathrm{~d}$ and daily data, respectively. Chanut et al. (2013) smoothed the displacement data over 2 or 4 weeks and at the same time, these authors computed weighted cumulative sums over months for the rainfall data. Vallet et al. (2013) emphasized that the monthly resolution is too low to resolve the impact of rainfall events on displacement rates. These same authors stressed that hourly time steps are unsuitable to capture the inertia of the hydrosystem that impacts landslide displacement rates, which was demonstrated by Helmstetter \& Garambois (2010). For all these reasons, we investigate here two data rates: daily and weekly (7-d) accumulated values.

\section{NON-PARAMETRIC AND FREQUENTIST CHANGE-POINT A NALYSIS}

\subsection{Method}

Different approaches have been developed to deal with the changepoint determination problem (see Horváth \& Rice 2014). Indeed, the detection of changes within series of observations arises in various branches of applied sciences: computer science for the detection of network intrusions and frauds (Yamanishi et al. 2000), bioinformatics for gene identification (Erdman \& Emerson 2007), finance for modeling, public health for routine disease surveillance (Salmon et al. 2014), ocean engineering for wave heights analysis (Killick et al. 2010), climatology for radiosonde data analysis (Lanzante 1996), seismology for earthquake rates (Touati et al. 2016), etc.

Lanzante (1996) fully described the procedure that we adopted for the analysis of our landslide data time-series. This is an iterative method designed to search for multiple change points in an arbitrary time-series. This approach, which uses resistant, 

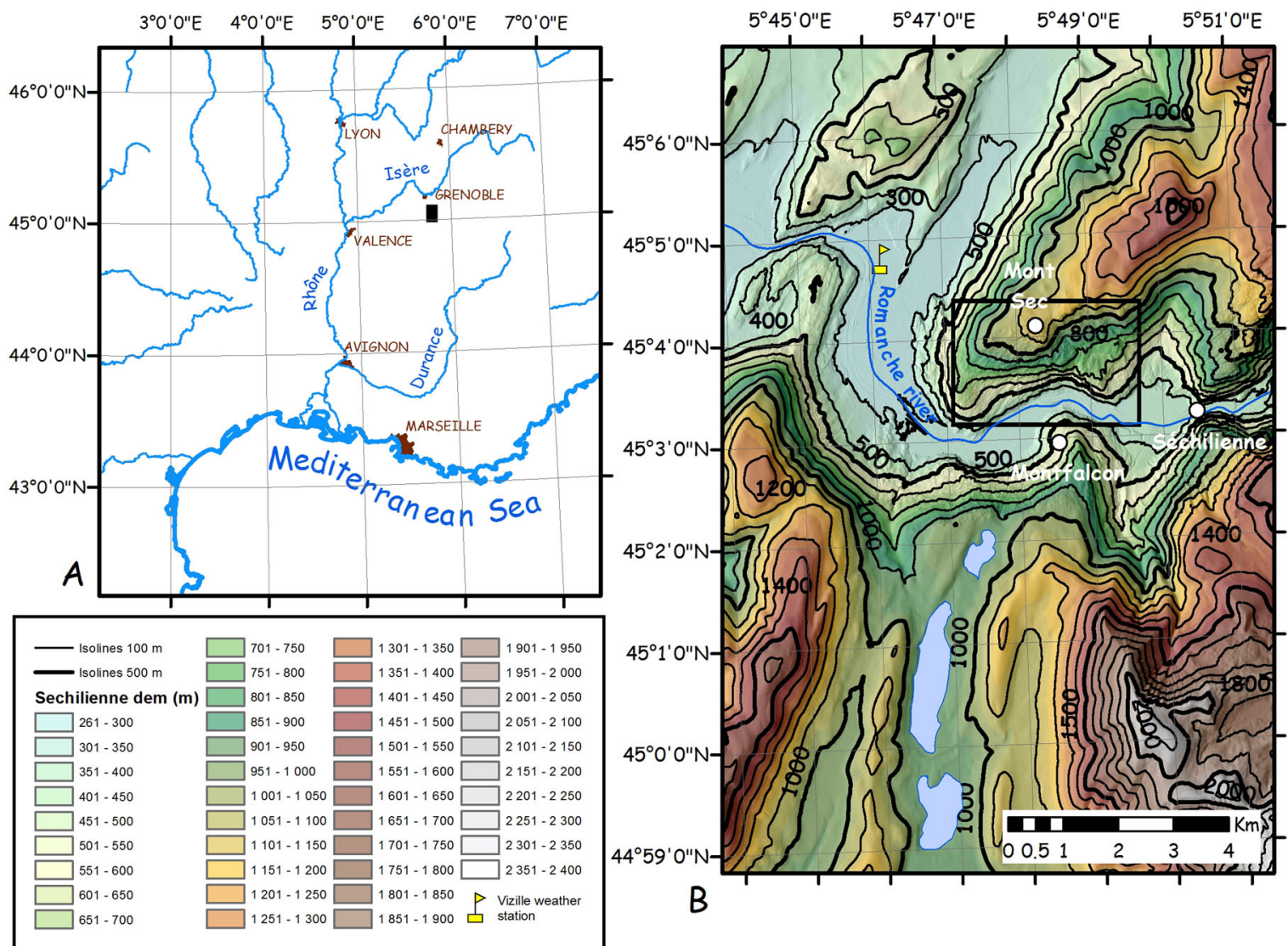

B

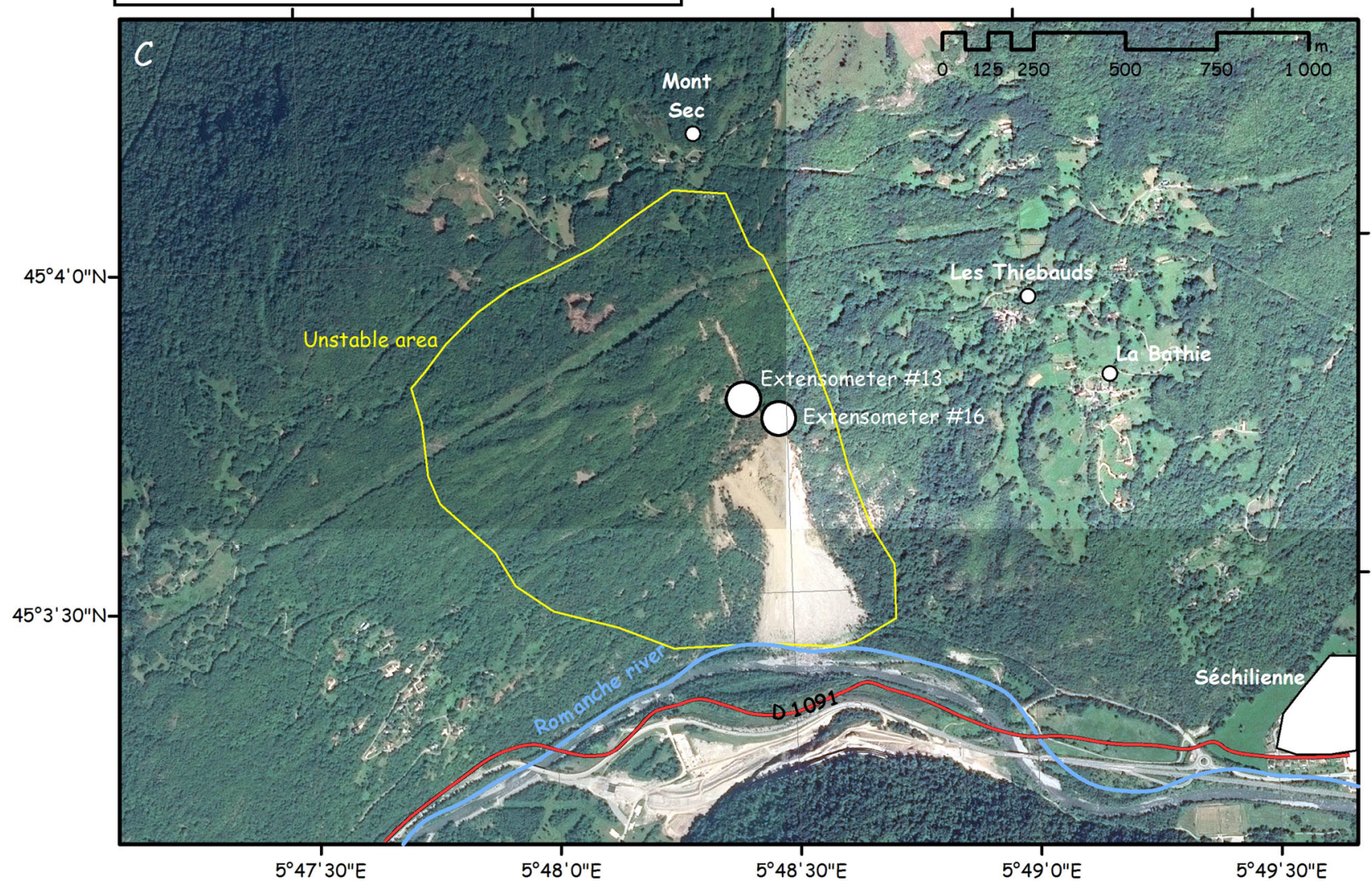

Figure 1. The Séchilienne rock avalanche location map. (a) Location of the studied area in SW of France. (b) Location of Séchilienne landslide on IGN RGEAlti $5 \mathrm{~m}$ dem. (c) SPOT 2014 image of the Séchilienne landslide. The extensometers 13 and 16 are displayed in white circles. The instable area is in yellow line. The projection used is Lambert Conformal Conic 93 and the Geographic Coordinate System is the GCS RGF 1993. 
robust and non-parametric statistical techniques, has already been applied successfully for the analysis of climate (Lanzante 1996; Lanzante et al. 2003) or seismological data (Amorèse 2007). Lanzante's method is an extension of the change-point test (Siegel \& Castellan Jr 1988). The test follows the classic Wilcoxon-MannWhitney (WMW) non-parametric test, also referred to as Wilcoxon rank sum test (Wilcoxon 1945) or the Mann-Whitney U test (Mann \& Whitney 1947). Only when the assumption of homogeneity of variances is made, the WMW test can be viewed as a median test. Nevertheless, the WMW test is basically a test for the difference of the sums of ranks of the observations under study. In Lanzante's method, it is in that light that the WMW test must be viewed, with the assumption that the difference in the sums of ranks mirrors the difference between statistical populations. Thus, the assumption of homogeneity of variances (identically distributed data) is not required in this application of the WMW statistics. The method can be called the rank-sum multiple change-point method (hereafter RSMCPM).

At each point $i$ in the series of $n$ points, the sum of the ranks $\left(\mathrm{SR}_{i}\right)$ from the beginning of the series to that point is calculated. Since the sum of the ranks depends on the number of points, $\mathrm{SR}_{i}$ is adjusted. Then, an adjusted value for the sum of the ranks, $\mathrm{SA}_{i}$, is:

$\mathrm{SA}_{i}=\left|\left(2 \mathrm{SR}_{i}\right)-i(n+1)\right|$

In the right-hand side of equation $(1), i(n+1)$, is connected with

$E\left(W_{i}\right)=i(n+1) / 2$

which is the expected value of the rank sum for the $i$ first observed ranks out of a total of $n$ points. The next step of the procedure is to find the maximum of $\mathrm{SA}_{i}$ to divide the series into two segments. The point $n_{1}$ being where the value of $\mathrm{SA}_{i}$ is maximum, the following variables are defined:

$W=\mathrm{SR}_{n_{1}}$

and

$n_{2}=n-n_{1}$.

After this, the WMW test is used to decide whether or not the null hypothesis (that there is no change in the sequence at $n_{1}$ ) is rejected, in favour of the alternative hypothesis. In this study, the chosen level of significance is 5 per cent as the generally accepted and expected alpha (type I error rate) value in most disciplines for statistical tests. The RSMCPM is applied to a given series as long as the statistical significance of each new change point is less than the specified significance level. For each iteration, a list of $N$ change points is delivered that defined $N+1$ segments. At each iteration, the series is adjusted by subtracting the median of its segment from each point.

Additionally to change-point significance probabilities and following Lanzante (1996), a signal-to-noise ratio (SNR) which quantifies the magnitude of each discontinuity is computed. For a given change point, this ratio appraises the variability associated with the shift in level between the adjacent segments relative to the variability within each segment:

$\mathrm{SNR}=\frac{S_{\mathrm{CP}}^{2}}{S_{N}^{2}}$

where $S_{\mathrm{CP}}^{2}$ is the variance owing to the shift in level between the segments adjacent to the change point and $S_{N}^{2}$ is the noise variance. The value of $S_{\mathrm{CP}}^{2}$ is (Lanzante 1996):

$S_{\mathrm{CP}}^{2}=\frac{n_{1}\left(\bar{X}_{1}-\bar{X}\right)^{2}-n_{2}\left(\bar{X}_{2}-\bar{X}\right)^{2}}{n-1}$ where $n_{1}$ and $n_{2}$ are the number of values in the left and right segments (segments are right-closed and left-open intervals) respectively $\left(n_{1}+n_{2}=n\right) . \bar{X}_{1}$ and $\bar{X}_{2}$ are the estimates of the mean values in these two segments. $\bar{X}$ is the overall mean:

$\bar{X}=\frac{n_{1} \bar{X}_{1}+n_{2} \bar{X}_{2}}{n}$.

The noise variance, $S_{N}^{2}$, is the variance of the combination of the two segments after they were normalized by subtracting $\bar{X}_{1}$ or $\bar{X}_{2}$ from all of the values in the left or right segment. It should be noted that the length for determining the SNR can be customized: 50 points away from the change point is the value recommended by Lanzante (1996). Larger values are prone to weaken the force and usefulness of SNR values. The SNR can be used to eliminate change points which are too 'weak'. Lanzante (1996) proposed an SNR value of at least 0.05 or 0.1 for 'important' change points.

In the comparison process of a part of the time-series with what has occurred before (or what will occur after), it is easy to understand that the centre of a segment which has a trend can be falsely identified as a change point, since the trend alters mean values. To overcome this drawback, Lanzante (1996) proposed a straightforward and effective solution: after each new change point is identified, both the $S_{N}^{2}$ (as described above) and a so-called 'trend noise variance' are computed and compared. If the trend slope is $b$, the trend noise variance, $S_{\mathrm{TN}}^{2}$, is the variance of the combination of the two segments after they were normalized by subtracting $b\left(x_{i}-x_{\mathrm{CP}}\right)$ from all of the values $y_{i}$ in the left and the right segments ( $x_{i}$ and $x_{\mathrm{CP}}$ are the $x$-values of $y_{i}$ and of the suspected change point, respectively). If the $S_{\mathrm{TN}}^{2}$ value is larger than the $S_{N}^{2}$ value, then the change point is validated, since the variability remains apparent in the trend noise variance (which is meant to be corrected from the trend bias). Otherwise $\left(S_{\mathrm{TN}}^{2}<S_{N}^{2}\right)$, a trend reduction is applied (by subtracting $b\left(x_{i}-x_{\mathrm{CP}}\right)$ from $\left.y_{i}\right)$ before the suspected change point is tested again.

Several parameters can be customized in the RSMCPM. The results of this study were obtained using values that we have defined as 'default values' for the algorithm:

(i) The default value for the significance level is 0.05 (Fisher 1925).

(ii) The default maximum number of points for the calculation of the SNR value is 50 points on both sides of the change point, which means a maximum number of 100 points for the calculation.

(iii) The default maximum number of iterations is 5 . The maximum number of iterations is unrelated to the possible number of change points: it concerns the maximum number of adjustments that are allowed until a new change point is detected.

(iv) The default minimum number of points at each end of the series is 2 .

(v) The default number of points (inter-change-point gap) between two consecutive change points is 2 .

(vi) The default threshold difference between $S_{\mathrm{TN}}^{2}$ and $S_{N}^{2}$ is 0 . This means that the trend reduction is applied whenever the discontinuity noise variance is larger than the trend noise variance. The larger the value of this threshold, the more restricted is the application of the trend reduction.

Since a decade, many approaches and software have addressed the determination of change points in univariate and/or multivariate time-series. Some Bayesian methods require independent Gaussian observations (Barry \& Hartigan 1993; Erdman \& Emerson 2007). As we will show in the next section, the condition of normality is not matched for our extensometer displacement data series. 
This limitation precludes the sustainable usage of the Erdman \& Emerson's method (2007) for our data set, whereas our technique works properly. Both type and shape of the probability distributions are not problematic for the RSMCPM. Nevertheless, this technique cannot be applied to continuous cumulative data, because, in common with many other methods of statistical inference, the WMW test also requires independence within groups (Hollander \& Wolfe 1973). As a final technical remark, one must note that the RSMCPM does not perform better than others technique when trying to detect change points close to the ends of the series. Actually, if the sum of the size of the two samples under comparison is smaller than 10 , no matter how much the two groups differ, the WMW test loses power (ability to reject a false null hypothesis): in this case, it fails to reach statistical significance at the level $\alpha=0.01$ for the two-sided problem. Thus, even a very strong change point may not be detected if it occurs in the ends of the series under study. Nevertheless, we guess the RSMCPM does not worse than other statistical methods when dealing with series ends.

\subsection{Method validation on geophysical time-series}

Before processing our landslide data, we validate the use of our rank-sum change-point detection algorithm on benchmark data: (i) the synthetic combination of normal distributions, investigated by James \& Matteson (2014), (ii) the annual January to June streamflow amounts for the Romaine river in Quebec, that has been explored by means of a Bayesian change-point approach in Perreault et al. (2000), and (iii) the Northern Hemisphere temperature from proxy data, A.D. 200-1995 (Jones \& Mann 2004; Matyasovszky 2011).

Fig. 2 shows the results of the RSMCPM, as applied to a synthetic combination of normal distributions. This is a modified version of the data example from James \& Matteson's (2014) study: a sequence of 100 independent samples from normal distributions $(\mathcal{N}(0,1), \mathcal{N}(0,3), \mathcal{N}(2,1)$ and $\mathcal{N}(2,4))$. The notation $\mathcal{N}(\mu, \sigma)$ means normally distributed with mean $\mu$ and standard deviation $\sigma$. We slightly upgrade this synthetic test by adding an extra $\mathcal{N}(0,3)$ very short (10 samples) segment at the end of the initial sequence. This extra tip is added (Fig. 2a) in order to assess the detection capability for a breakpoint close to series' end, where an edge effect may be significant. In Fig. 2(b), a 5 per cent slope is added to the synthetic series of Fig. 2(a) to simulate a series with upward trend. As can be seen (Fig. 2a), the method has difficulty identifying changes in standard deviation (the first breakpoint is missed), but it is perfectly successful for the detection of the change in mean at index 200. Even close to the series' end (Fig. 2a), the final breakpoint (index 400) is detected. Nevertheless, the results for this point are not accurate (index 389). When the series shows a trend (Fig. 2b), the first breakpoint is mislocated and the final breakpoint is missed, but there is no detection of extra change points. As comparison across approaches, a divisive hierarchical estimation algorithm for multiple change-point analysis (James \& Matteson 2014) is applied and gives the results displayed in Figs 2(c) and (d). By doing so, we mimic one of the examples proposed by James \& Matteson (2014) to illustrate the use of their divisive algorithm, except that these authors did not examined the case in which the data show a trend. We show that the James \& Matteson's (2014) algorithm misses the second and the last breakpoints in Fig. 2(c) and it detects many fictitious breakpoints in the series that shows a trend (Fig. 2d).

As a second example, we partly revisited the 1970-2000 streamflow time-series for Northern Quebec Labrador region (Perreault et al. 2000). These authors used a Bayesian change-point analysis to suggest a change in the average streamflow of rivers that occurred in 1984. Fig. 3(a) displays the marginal posterior probability density function of the change point for the Romaine river, as obtained from the Bayesian change-point analysis (Perreault et al. 2000). The RSMCPM (Fig. 3b) achieves similar results than Perreault et al.'s (2000) results but we resolve an additional breakpoints in 1976 with a significant SNR (0.32). One must note that the 1984 change point is quantified by a strong SNR value (2.35).

As a third test, we use the temperature time-series (A. D. 200-1995) for the Northern Hemisphere (Jones \& Mann 2004; Matyasovszky 2011). The list of abrupt changes detected in the Northern Hemisphere temperature values for the period 200-1995 includes the years 825, 1296, 1387, 1656, 1749 and 1883 (Fig. 4a). These values are obtained from the kink point analysis conducted by Matyasovszky (2011). The coldest and the warmest intervals in the past centuries are conventionally labeled the Little Ice Age (LIA) and the Medieval Warm Period (MWP). There is no broadly accepted definition of these climate epochs (Bradley et al. 2003). Matyasovszky (2011) pinpoints two phases in the LIA: a stronger and longer period (1387-1656) and a weaker and shorter time interval (1749-1883). For Matyasovszky (2011), the MWP lies between years from 795 to 1120 . Our method detects six breakpoints (Fig. 4b). They show rather compelling (larger than 0.05) SNR values (they are ranging from 0.06 to 0.97 ). Nevertheless, a warmer temperature segment is found from 780 to 1119 and the possibility of three distinct phases in the LIA (1252-1444, 1444-1718 and 17181845 ) is not ruled out. The results from the RSMCPM agree well with the definition of the LIA proposed by Matyasovszky (2011). Moreover, our results are highly consistent with the definitions suggested by Yan et al. (2015). For these authors, the beginning of the MWP is A.D. 800 and they suggest that the transition between MWP and LIA should be linked to the timing of 1246 A.D. being the last time in which the perihelion of the Sun-earth orbit coincided with Northern Hemisphere winter solstice.

The three comparisons show that the RSMCPM algorithm is able to yield useful and convincing results. The method provides three main advantages for landslide displacement rate analysis:

(i) It holds few assumptions, especially the non-Gaussian character of data does not affect results.

(ii) The existence of a trend in the serial data is not a critical issue.

(iii) SNR values are helpful in inferring hierarchies in change points.

\section{RESULTS}

The cumulative displacement curve from extensometer 13 at Séchilienne (Fig. 5) shows very gradual daily variations: the average displacement rate is about $3.5 \pm 2.9(\mathrm{SD}) \mathrm{mm} \mathrm{d}^{-1}$. The median is $2.4 \mathrm{~mm} \mathrm{~d}^{-1}$. The average rate is rather small compared to its variability. This high variability does not result from extreme values: the interquartile range, which is a resistant estimate of the dispersion, is still $3.2 \mathrm{~mm} \mathrm{~d}^{-1}$ for the Séchilienne data, as to compare with the 3.5 and $2.4 \mathrm{~mm} \mathrm{~d}^{-1}$ average and median values. Extensometer measurements may be daily disturbed by the weather (wind, frost) and it is hardly surprising that these data show relatively large dispersion values. Daily variations of displacements are overall very gradual but the series show local abrupt changes (Fig. 5). In the daily displacement curve (Fig. 6a), four change points are identified, respectively located at 2008.400 (2008 May 26), 2010.812 (2010 October 24), 2012.728 (2012 September 23) 

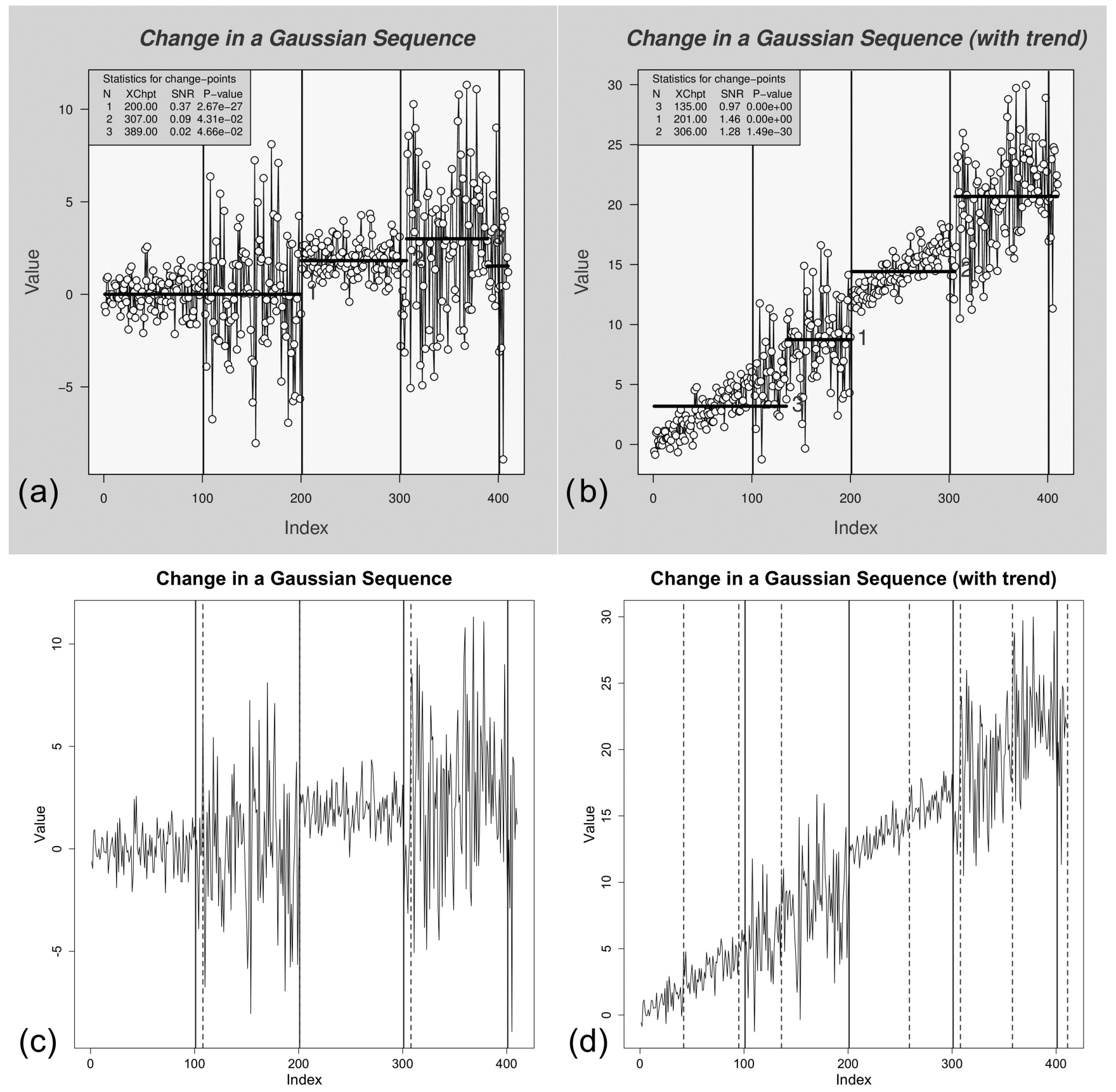

Figure 2. Simulated independent Gaussian observations with changes in mean or variance. (a) Change-point locations estimated by the rank sum method. Solid vertical lines indicate the true change-point locations. Estimated change-point locations are marked by numbers (1, 2 and 3). (b) Change-point locations estimated by the rank sum method when a 5 percent trend is added to the series in (a). (c) Change-point locations estimated by the E-Divisive method. In this part of the figure, dashed vertical lines indicate the estimated change-point locations. For details, please refer to fig. 1 in James \& Matteson (2014). (d) Change-point locations estimated by the E-Divisive method when a 5 per cent trend is added to the series in (a).

and 2014.193 (2014 March 12). The SNR values for these change points are $1.01,0.40,0.49$ and 3.63 , respectively (Table 1 ). These results suggest that all the change points are important (SNR values larger than 0.05 ). In order to smooth down the daily fluctuations, we apply the RSMCPM to weekly (7 d) displacement data (Fig. 6a). In the weekly displacement curve (Fig. $6 \mathrm{~b}$ and Table 2), four change points are identified, respectively, located at 2008.400 (2008 May 26), 2009.914 (2009 November 30), 2009.971 (2009 December 21) and 2012.712 (2012 September 17). One of these change points is minor, as it shows an SNR value of $4 \times 10^{-3}$ (2009.914, Table 2).
One must note that the change points from daily windows, with the two largest SNR values, do fit the one of the weekly window (2008 May and 2012 September). As an aside, for daily window data, Shapiro-Wilk normality tests (Shapiro \& Wilk 1965) reveal that the data of each segment are unlikely to be Gaussian (the $p$-value for the tests are all smaller than $2 \times 10^{-10}$ ). This finding provides sound justification for using the RSMCPM rather than a change-point detection method that requires data normality.

The average rainfall rate is about $2.5 \pm 4.8(\mathrm{SD}) \mathrm{mm} \mathrm{d}^{-1}$. For this data set too, the variability is high compared with the mean value: 


\section{Romaine River Streamflow Change Point Analysis}
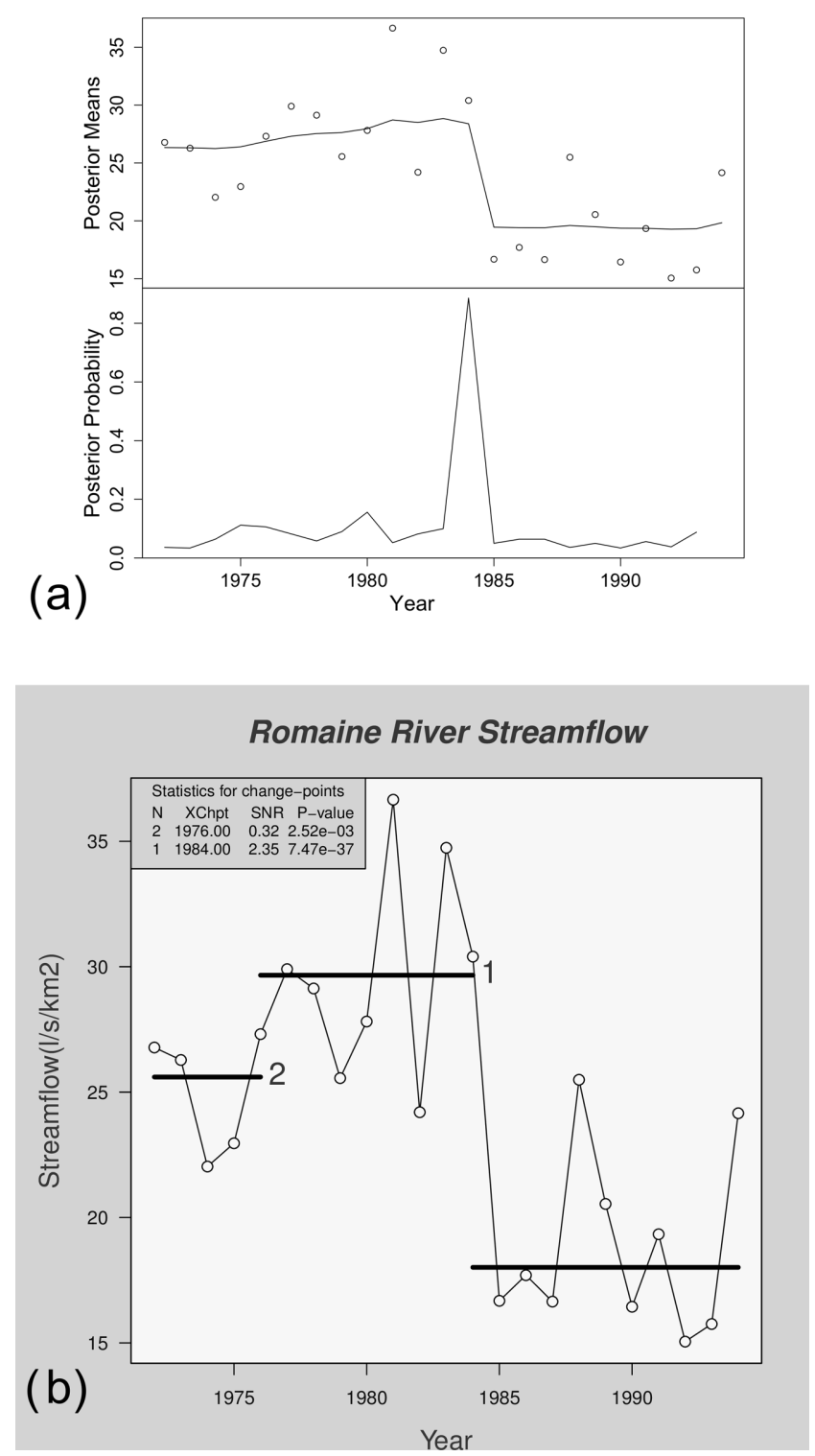

Figure 3. Annual January to June streamflow amounts for the Romaine river in Quebec. (a) Change-point locations estimated by the Bayesian changepoint analysis. The 'Posterior Means' displays the data along with the posterior mean of each position. The peak value of the posterior probability marks the change-point location. For details, please refer to Erdman \& Emerson (2007). (b) Change-point locations estimated by the rank sum method. Estimated change-point locations are marked by numbers (1 and 2).

the coefficient of variation ( $c v$, ratio of the standard deviation to the mean) of the series is about 1.9. Values in the daily rainfall data series are varying quickly (Fig. 7a). A Wald-Wolfowitz test (Wald \& Wolfowitz 1943), designed to check independence and stationarity, confirms that the daily series is not stationary. Change points (or trends) are signs of non-stationarity. Nevertheless, local homogeneity in the time-series, as evidenced by the Wald-Wolfowitz test, is required to allow their detection. This may explain the RSMCPM fails in detecting any change point in the daily rainfall series (the figure is not shown). In the weekly rainfall curve (Fig. 7b), the RSMCPM is successful and detects five change points located at 2007.289 (2007 April 16), 2007.864 (2007 November 12), 2009.875
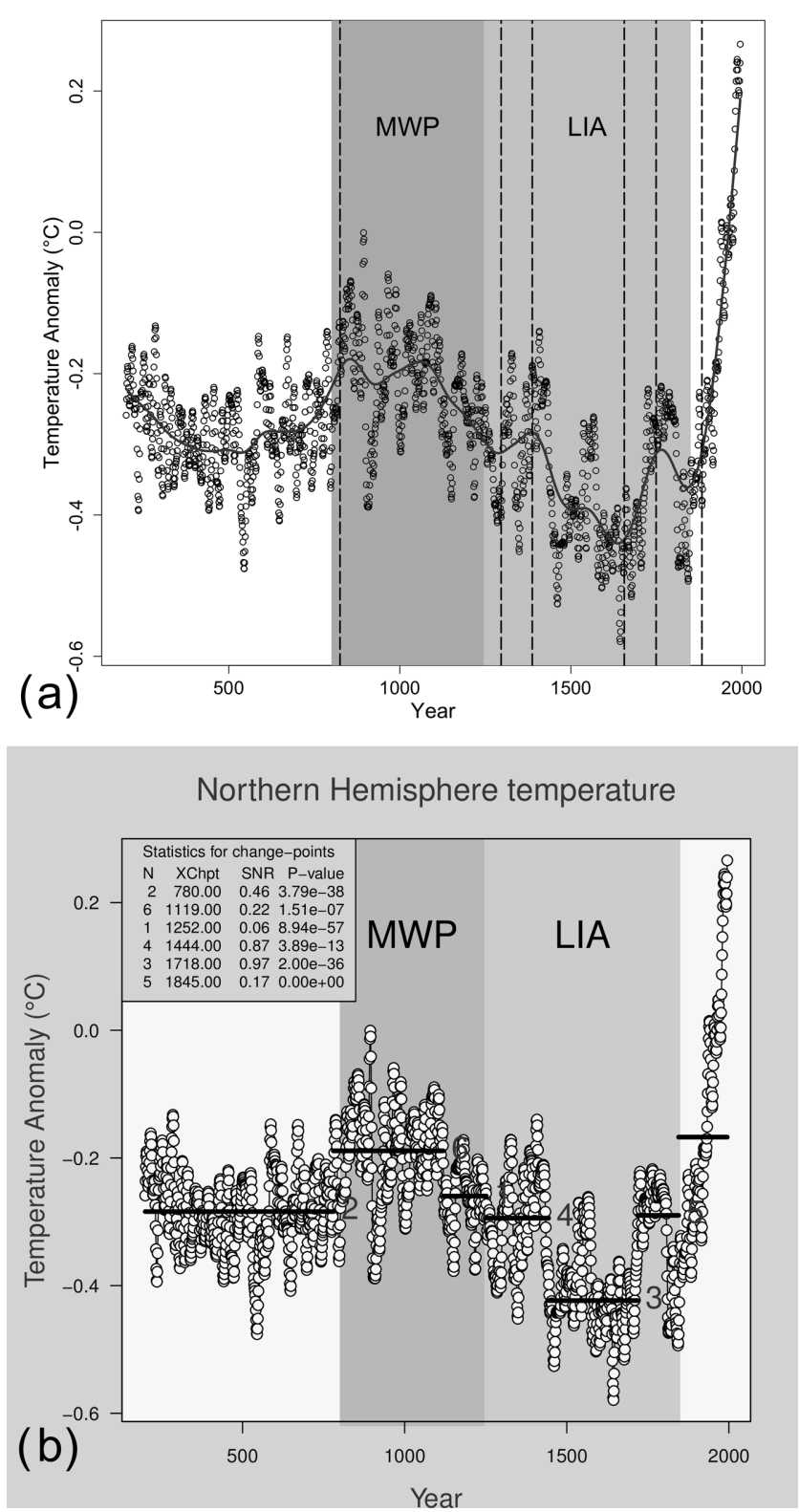

Figure 4. Northern Hemisphere temperature from proxy data, A.D. 2001995. (a) Change-point locations estimated by the kink point analysis. A cubic smoothing spline fits the data (solid line) and reveals the kink points. Dashed vertical lines indicate the estimated change-point locations. (b) Change-point locations estimated by the rank sum method. The grey shaded zones represent the Medieval Warm Period (MWP) and the Little Ice Age (LIA) as defined as the 800-1246 and 1246-1850 time intervals, respectively.

(2009 November 16), 2012.253 (2012 April 02) and 2014.590 (2014 August 04), respectively (Table 2). Three points are increases and two are decreases. Only one increase (2009.875), the smallest one, correlates in time with a displacement rate change. It suggests other control parameters for the 2008 and 2012 change points we resolved in weekly displacement rates.

Data from another extensometer (extensometer 16; see (Fig. 1 for location) help to improve our understanding of the results: our procedure highlights similar change points in the two daily and weekly displacement series for both extensometers (Figs 6 and 8 and Tables 1 and 2). This outcome provides further evidence that results of our procedure are robust. Nevertheless, the series for 


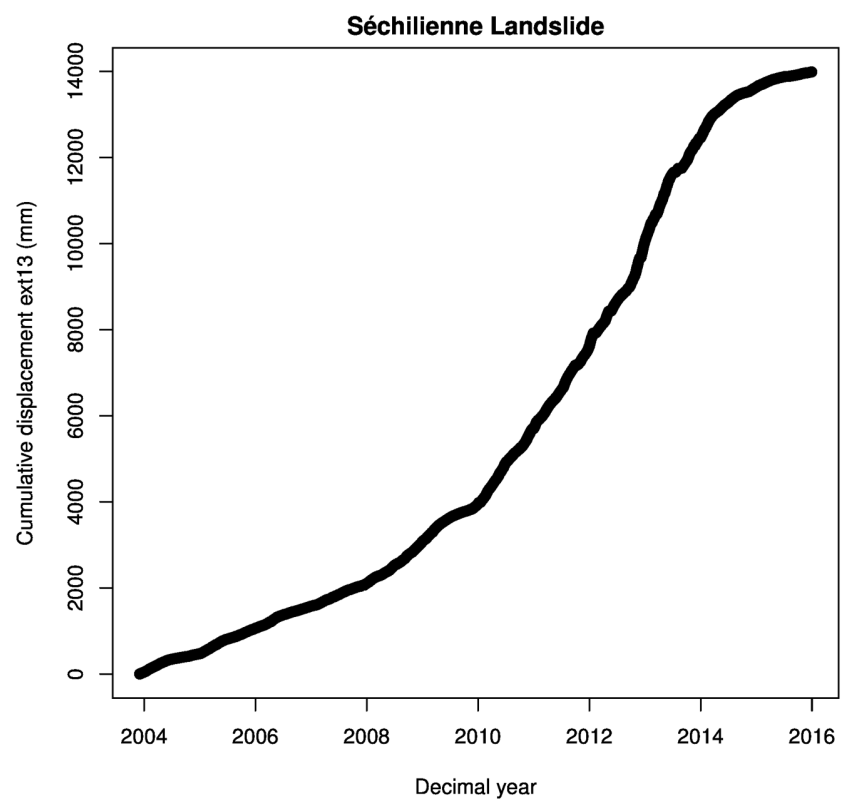

Figure 5. Cumulative displacement plot at Séchilienne extensometer 13.

extensometer 16 show fewer change points than the series for extensometer 13: for the daily series, only two minor change points are detected, located in 2014 March (2014 March 08 and 11). For the weekly series, the extensometer 16 show paramount change points: they both show SNR values larger than 1 (1.17 and 1.59, respectively). The first change point is perfectly coincident with one change point of the weekly series for extensometer 13 (2009 November 30). The second change point (2014 March 10) is concomitant with the change points of 2014 March in the daily series. To summarize, four pivotal times are highlighted in the Séchilienne displacement time-series: 2008 May, 2009 November-December, 2012 September and 2014 March. The strongest change points (SNR values greater than 1) are always common to several series (extensometers 13 and 16 or daily and weekly series): $2008.400,2009.914$, 2014.188 and 2014.193. The largest SNR values for these points are $1.01,1.17,1.59$ and 3.63, respectively. Several change points in the daily and weekly series for the extensometer 13 (Tables 1 and 2) may be considered as local features: 2010.812 (2010 October 24), 2012.712 (2012 September 17 in the weekly series) and 2012.728 (2012 September 23 in the daily series).

\section{DISCUSSION AND CONCLUSION}

For the three calibration data sets we perform, the RSMCPM is undoubtedly efficient in addressing properly the double challenge of the multiple change-point problem: finding the optimal number and finding the location of change points. The procedure is effective even under adverse conditions: the first (synthetic) example shows that the procedure is successful in detecting change points close to a series' end and when there is a trend in the series. The second example illustrates how the technique is conducive in detecting change points in sparse series. The last example reveals that the method may be helpful when change points in a series are subject to various interpretations, as is the case for historical climate data. The main objective of the study is to apply the change-point method to a landslide displacement and rainfall time-series and to compare the results with previous analysis. For the time range spanning from 2003 to 2013, Chanut et al. (2013) labeled five different phases in

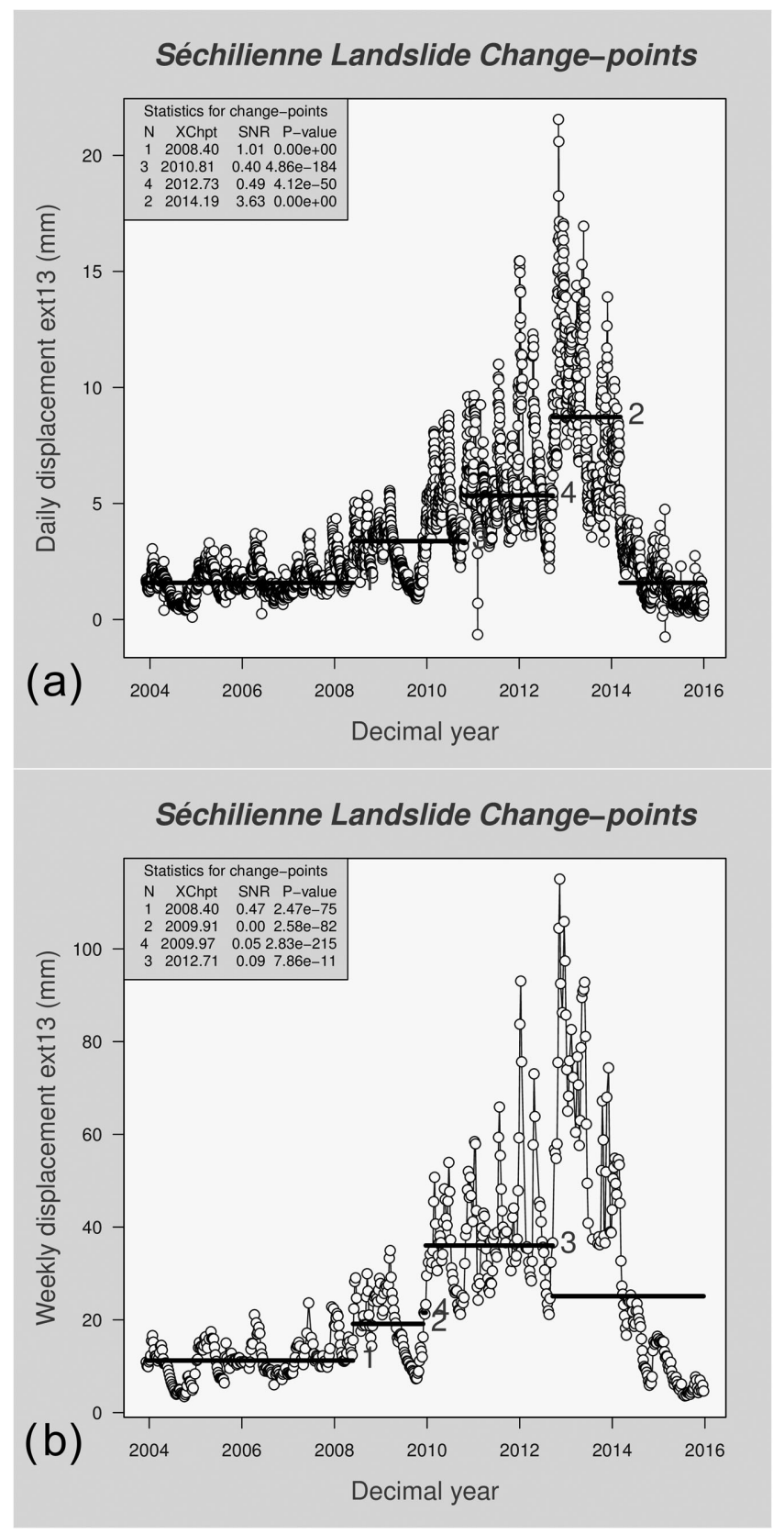

Figure 6. Displacement plots for the Séchilienne extensometer 13. (a) Change point detected by the rank sum method in the daily displacement time-series. The change points are, respectively, located at 2008.400 (2008 May 26), 2010.812 (2010 October 24), 2012.728 (2012 September 23) and 2014.193 (2014 March 12). (b) Change points detected by the rank sum method in the weekly displacement time-series. The change point are, respectively, located at 2008.400 (2008 May 26), 2009.914 (2009 November 30), 2009.971 (2009 December 21) and 2012.712 (2012 September 17).

the landslide displacement rate: three slow ones (called R2, R3 and $\mathrm{R} 5$, showing displacement rates about or less than $50 \mathrm{~mm} \mathrm{month}^{-1}$ ) and two fast ones (R4 and R6 showing displacement rates equal or larger than $100 \mathrm{~mm} \mathrm{month}^{-1}$ ). Chanut et al. (2013) set the start times of R3, R4, R5 and R6 on 2005, 2008, 2009 and 2010 January, respectively [fig. 4 in Chanut et al. (2013)]. No indication is given by Chanut et al. (2013) on the way these phases are identified. The RSMCPM partly mirrors the segmentation of the series proposed by Chanut et al. (2013) (Fig. 9 and Tables 2 and 3), as the two study 
Table 1. Statistics of the change points for each series (daily bins). $\beta$ is for the 'biweight mean'.

\begin{tabular}{lcccccc}
\hline $\begin{array}{l}\text { Data } \\
\text { set }\end{array}$ & $\begin{array}{c}\text { Date } \\
\text { (decimal/ymd) }\end{array}$ & $\begin{array}{c}\text { SNR } \\
\text { value }\end{array}$ & $\begin{array}{c}\text { Left } \beta \\
\left(\mathrm{mm} \mathrm{d}^{-1}\right)\end{array}$ & $\begin{array}{c}\text { Left } \beta \\
\left(\mathrm{mm} \mathrm{month}^{-1}\right)\end{array}$ & $\begin{array}{c}\text { Right } \beta \\
\left(\mathrm{mm} \mathrm{d}^{-1}\right)\end{array}$ & $\begin{array}{c}\text { Right } \beta \\
\left(\mathrm{mm} \mathrm{month}^{-1}\right)\end{array}$ \\
\hline Ext 13 & 2008.400/2008 May 26 & 1.01 & 1.6 & 48.2 & 3.4 & 103.0 \\
Ext 13 & 2010.812/2010 Oct 24 & 0.40 & 3.4 & 103.0 & 5.3 & 163.0 \\
Ext 13 & 2012.728/2012 Sept 23 & 0.49 & 5.3 & 163.0 & 8.7 & 266.2 \\
Ext 16 & 2014.182/2014 Mar 08 & $<2.3 \times 10^{-5}$ & 4.0 & 122.6 & 3.7 & 111.3 \\
Ext 16 & 2014.190/2014 Mar 11 & 0.03 & 3.7 & 111.3 & 1.4 & 41.9 \\
Ext 13 & 2014.193/2014 Mar 12 & 3.63 & 8.7 & 266.2 & 1.6 & 48.2 \\
\hline
\end{tabular}

Table 2. Statistics of the change points for each series (weekly bins). $\beta$ is for the 'biweight mean'.

\begin{tabular}{lcccccc}
\hline $\begin{array}{l}\text { Data } \\
\text { set }\end{array}$ & $\begin{array}{c}\text { Date } \\
(\text { decimal/ymd) }\end{array}$ & $\begin{array}{c}\text { SNR } \\
\text { value }\end{array}$ & $\begin{array}{c}\text { Left } \beta \\
\left(\mathrm{mm} \mathrm{week}^{-1}\right)\end{array}$ & $\begin{array}{c}\text { Left } \beta \\
\left(\mathrm{mm} \mathrm{month}^{-1}\right)\end{array}$ & $\begin{array}{c}\text { Right } \beta \\
\left(\mathrm{mm} \mathrm{week}^{-1}\right)\end{array}$ & $\begin{array}{c}\text { Right } \beta \\
\left(\mathrm{mm} \mathrm{month}^{-1}\right)\end{array}$ \\
\hline Rainfall & 2007.289/2007 Apr 16 & 0.04 & 12.5 & 54.7 & 18.0 & 78.5 \\
Rainfall & 2007.864/2007 Nov 12 & 0.01 & 18.0 & 78.5 & 15.7 & 68.4 \\
Ext 13 & 2008.400/2008 May 26 & 0.47 & 11.2 & 48.9 & 19.1 & 83.3 \\
Rainfall & 2009.875/2009 Nov 16 & 0.0007 & 15.7 & 68.4 & 16.4 & 71.4 \\
Ext 13 & 2009.914/2009 Nov 30 & 0.004 & 19.1 & 83.3 & 21.5 & 93.9 \\
Ext 16 & 2009.914/2009 Nov 30 & 1.17 & 19.8 & 86.3 & 43.7 & 190.3 \\
Ext 13 & 2009.971/2009 Dec 21 & 0.05 & 21.5 & 93.9 & 36.0 & 157.0 \\
Rainfall & 2012.253/2012 Apr 02 & 0.06 & 16.4 & 71.4 & 22.8 & 99.5 \\
Ext 13 & 2012.712/2012 Sept 17 & 0.09 & 36.0 & 157.0 & 25.1 & 109.3 \\
Ext 16 & 2014.188/2014 Mar 10 & 1.59 & 43.7 & 190.3 & 9.9 & 43.3 \\
Rainfall & 2014.590/2014 Aug 04 & 0.05 & 22.8 & 99.5 & 18.2 & 79.3 \\
\hline
\end{tabular}

periods do not overlap exactly (2003-2013 and 2004-2015). Our S1 slow stage covers the timespan of the Chanut et al.'s (2013) R2 and R3 slow phases. Our moderately fast S2 stage can be related to the R4 and R5 phases (however, any slow phase such as R5 is not highlighted by the RSMCPM during the S2 stage). The fast S3 stage begins almost at the same time as the R6 phase. Since the study series is longer than Chanut et al.'s (2013) and continues beyond 2013, we detect two additional stages: the very fast stage S4, beginning at the end of 2012 and the slow phase S5, beginning at the start of 2014. Fig. 9 summarizes this stage analysis.

The RSMCPM does not have, as any statistical tools, the capacity to explain the origin of a shift in the study time-series. Nevertheless, it provides information on key stages for temporal change in the landslide kinematics. Except for the 2009 November 16 weak breakpoint in the rainfall series, there is no relationship between the rainfall and the displacement breakpoints: the 2012 April 02 change point in the rainfall data highlights an increase of 39 per cent for the biweight mean (Tukey 1960) of rainfall, but there is no equivalent change in displacement rate for the weekly series comparable to that in rainfall. The 2014 August 04 change point in the rainfall data is located long after the 2014 March 10/12 decrease in displacement rate (from 190-270 to $40-50 \mathrm{~mm} \mathrm{month}^{-1}$ ). Minor change points in the rainfall data like the 2007 April 16 and the 2007 November 12 discontinuities are not associated with any change point in the displacement series (Fig. 9 and Tables 2 and 3). In the same way, the 2008 May 26 increase in displacement rate is observed with no significant changes in rainfall to be related to (Figs 5 and 6). All this suggests that an increase of the rainfall is able to induce an increase of the landslide displacement rate (that is the case for the 2009 November-December breakpoint), but that most of the dynamics of the landslide is not directly attributable to rainfall increase/decrease. The detailed exploration of the characteristics of the five kinematic stages (Fig. 10) suggests that the displacement rate is tied in with the rainfall intensity but clearly there is no one-to-one correspondence between the displacement rate and a given rainfall amount (as an example, points S2 and S3 show almost the same rainfall rates for very different displacement velocities in Fig. 10a). This is consistent with displacements weakly correlated with rainfall on Séchilienne site (Chanut et al. 2013; Klein et al. 2013).

The relation of the mean displacement rate with the rainfall frequency is more pronounced than with the rainfall intensity (Figs 10a and b). In Fig. 10(a), point S3 (stage S3) shows a larger displacement rate for a lower rainfall intensity than point S2 (stage S2). The relation becomes monotonic for the frequency of rainy days (Fig. 10b). Except for the last stage (S5), it appears that the mean displacement rate is directly connected to the frequency of rainy days (Fig. 10b). This observation appears consistent with the previous finding that landslide kinematics is dependent upon not only rainfall but also soil moisture conditions (Ponziani et al. 2012; Brocca et al. 2016; Greco \& Bogaard 2016; Bogaard \& Greco 2017). The correlation between the frequency of rainfall events and soil moisture levels is an unremarkable fact and several environmental studies confirmed that soil moisture is more strongly related to precipitation frequency than precipitation amount (e.g. Piao et al. 2009; Wu et al. 2012). The last stage (stage S5) seems to be located in an unexpected place of our bivariate plot: it shows almost the same mean displacement rate than stage S1 for a quite larger frequency of rainfall events. We can guess that the fracture opening within the rockslide and the resulting fall in pore pressure hinders the displacement during this last stage.

A remarkable shift in the displacement rate from S2 to S3 is evident in Fig. 10: the Séchilienne rock avalanche reached a new level of displacement rates in 2010. It is important to recognize that in 2009 September, the French government declared a state 

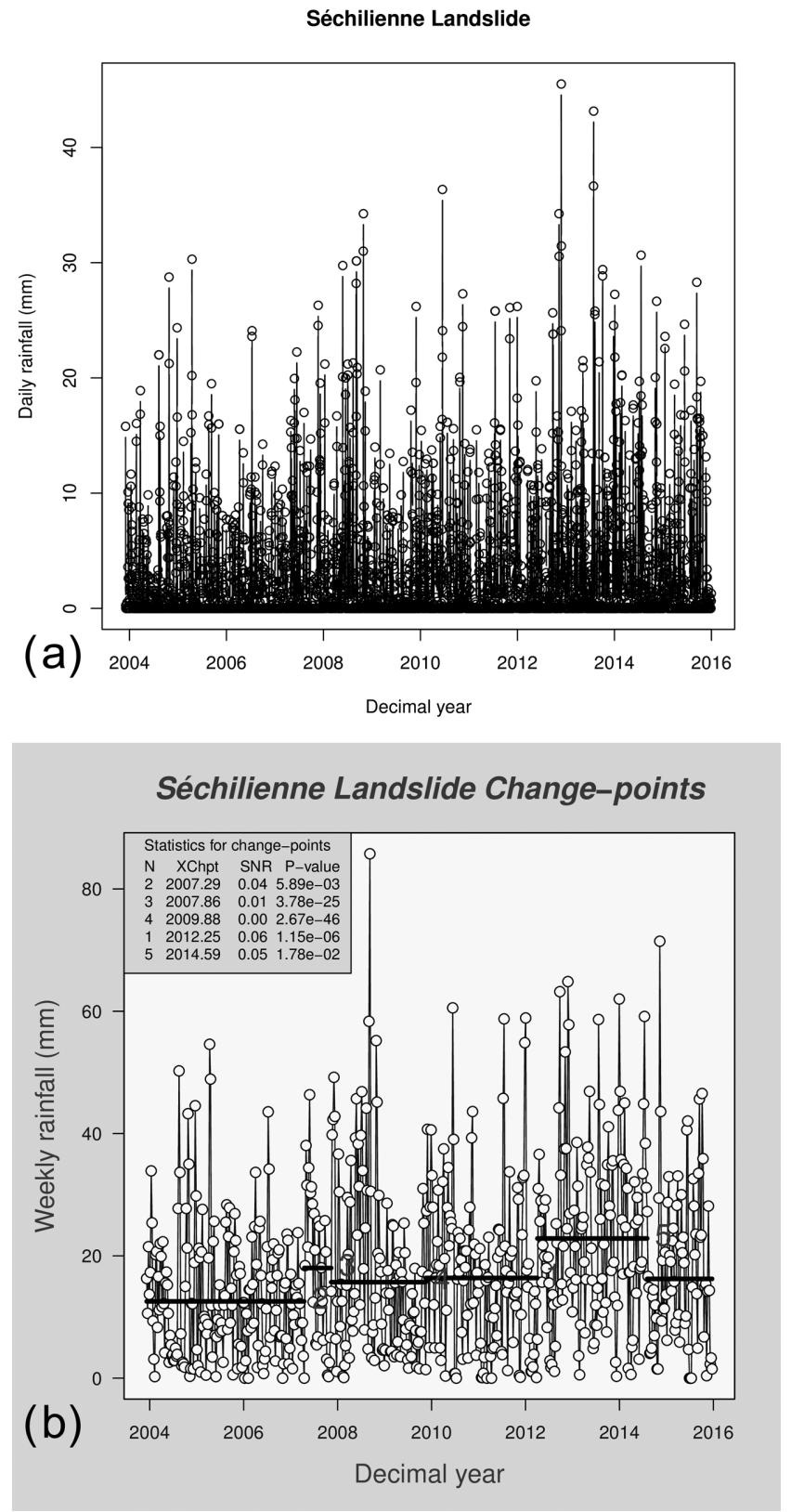

Figure 7. Rainfall plots for the Vizille weather station. (a) Daily rainfall. (b) Change point detected by the rank sum method in the weekly rainfall time-series. The change points are located at 2007.289 (2007 April 16), 2007.864 (2007 November 12), 2009.875 (2009 November 16), 2012.253 (2012 April 02) and 2014.590 (2014 August 04), respectively.

of drought emergency for the administrative region in which the Séchilienne rock avalanche is situated. In this way, stage 2 is associated with the period billed as the driest period for the study time range (2004-2015). This is consistent with our rain information during S2 showing both small rainfall and small rainy day frequency (Fig. 10). There can be questions about a possible non-linear response of the landslide to precipitation trigger after the drought. The change point that starts S3 stage is strong. The occurrence of a stage (S3) with very high displacement rates specifically just after the period of severe drought may be not without significance. Whereas Cappa et al. (2014) underlined a background seasonality of dry and wet seasons on displacement rates, our change-point analysis emphasizes the impact of an exceptional dry year on the

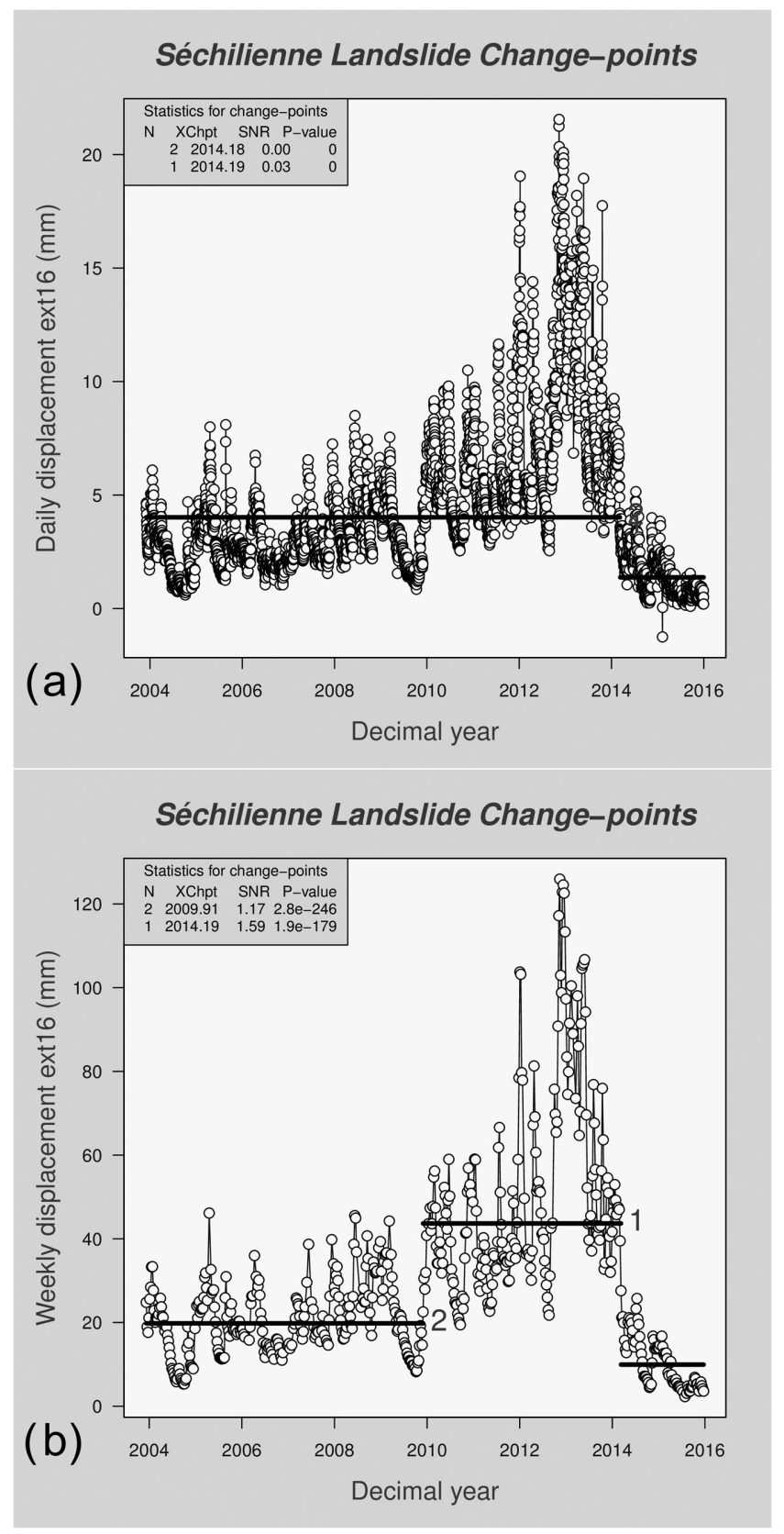

Figure 8. Displacement plots for the Séchilienne extensometer 16. (a) Change point detected by the rank sum method in the daily displacement time-series. The change points are, respectively, located at 2014.182 (2014 March 08) and 2014.190 (2014 March 11). (b) Change point detected by the rank sum method in the weekly displacement time-series. The change points are, respectively, located at 2009.914 (2009 November 30) and 2014.188 (2014 March 10).

landslide kinematics. As such the second part of 2009 is a period of weak brittle deformation (few quakes and rockfalls) as suggested by Fig. 2 (p. 28) in the SLAMS project's final report (Garambois 2014). Fig. 11 clearly shows that the response of the landslide to precipitation trigger is stronger after the 2009 drought.

Rainfall is a well-identified cause of landslide triggering (Hufschmidt \& Crozier 2008; Tatard et al. 2010; Greco \& Bogaard 2016). For the Séchilienne landslide, we already know that rockfalls and microseismicity are correlated with a vanishing value, if any, for time lag with rainfall (Helmstetter \& Garambois 2010; 


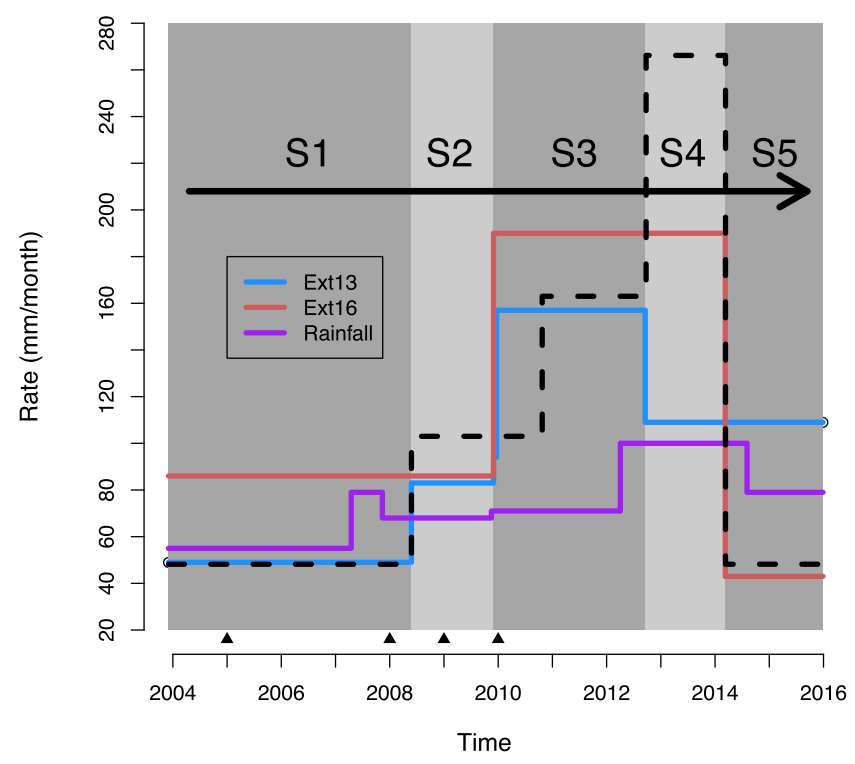

Figure 9. The stage timeline. Filled triangles just above the $x$-axis show the start times of the kinematic stages suggested by Chanut et al. (2013). The dashed line indicates the breakpoint sequence for the daily series of extensometer 13.

Klein et al. 2013). Our comparison of rainfall and displacement rate breakpoints is deficient (it is likely that the RSMCPM may not pickup all the possible breakpoints in the rainfall series, as the WMW test is implemented to reduce the risk of false positive), nevertheless it is notable that very intense rainfall events broke out:

(i) just before the 2008 May 26 increase in displacement, from May 24 to 26 (64 mm collected over three successive days);

(ii) on 2009 November-December, in the time period of the 2009 November 30 and the 2009 December 21 increases in displacement rates. From November 28 to 29 and from December 21 to December 24 , about $90 \mathrm{~mm}$ were collected ( 46 and $43 \mathrm{~mm}$ during each rainfall event, respectively);

(iii) on September 22, before the 2012 September 23 displacement rate breakpoint (about $100 \mathrm{~mm}$ rainfall were collected over five successive days, from 2012 September 22 to September 26).

This is confirmed in an Event Coincidence Analysis performed using the CoinCalc R package (Siegmund et al. 2017). We do not fail to reject at the 0.05 level (the $p$-value for the precursor/trigger coincidence significance test, from randomly shuffled series, is 0.001 ) the null hypothesis that the observed number of coincidences between displacement breakpoints and heavy rainfall can be explained by two independent series of randomly distributed events (Fig. 12). The coincidence of the starts of displacement phases S2, S3 and S4 with heavy rainfall events is unquestionable (Fig. 12).

At any rate, our result are conclusive, as being able to quantitatively define stages in an apparent continuous divergence of the cumulative displacement. The ability to define stages in the $10 \mathrm{yr}$
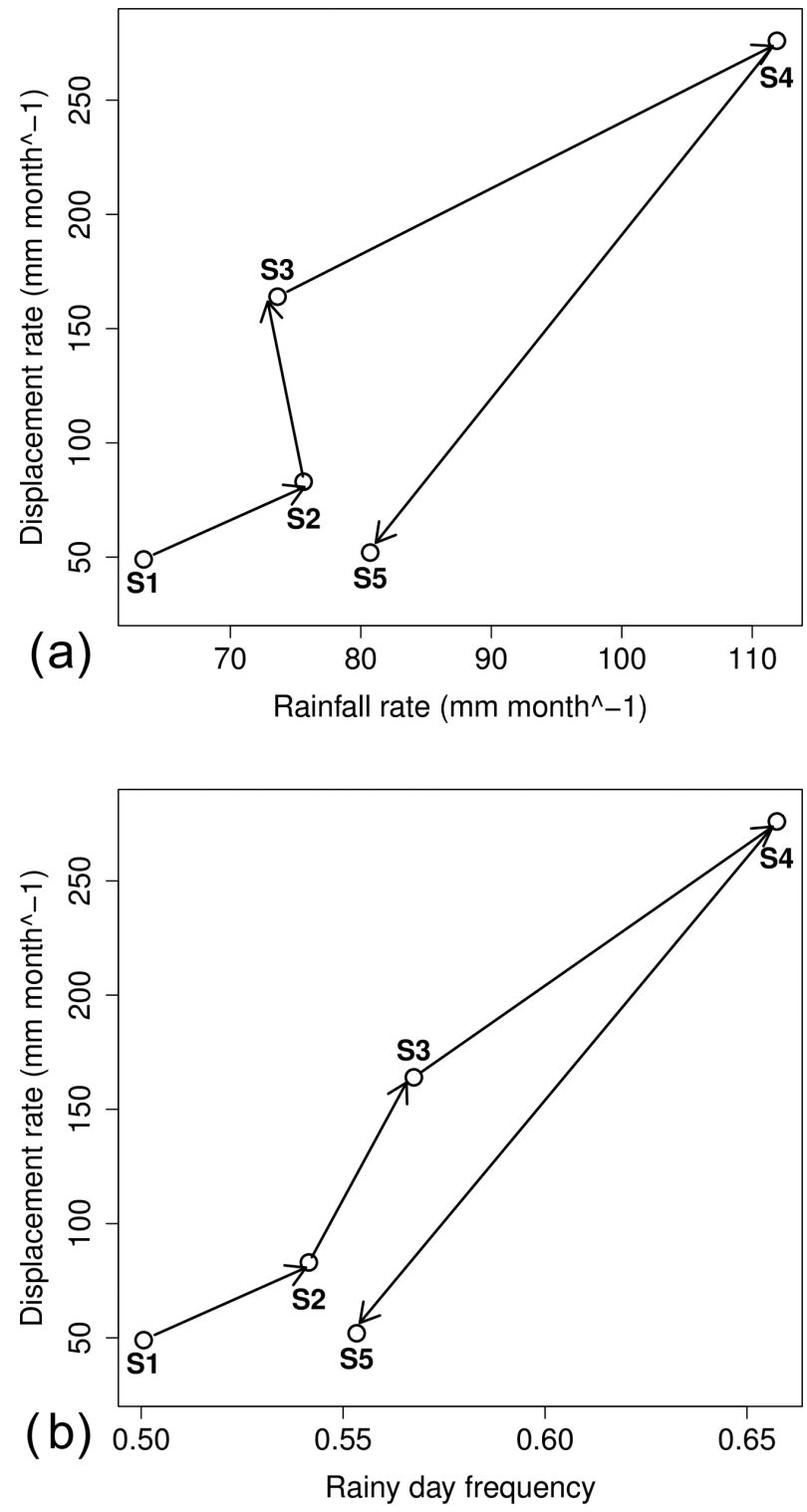

Figure 10. Bivariate plots of the relations between displacement rates and rain information for each displacement stage (S1-S5). Arrows follow the time sequence. (a) Mean displacement rate-Mean rainfall. (b) Mean displacement rate-Rainy day frequency. We define as a rainy day a day on which the rainfall is larger than zero.

duration of the acceleration of Séchilienne rock avalanche displacement (from 2004 to 2014) demonstrates the process is still susceptible to external forcing (e.g. rainy day frequency). The results obtained from the retrospective use of our change-point analysis show that averaging on different time windows helps in understanding the kinematics of the Séchilienne rock avalanche. The odds are pretty good this kind of innovative approach will be also profitable

Table 3. Kinematics stages in the last decade (displacement values are from the extensometer 13).

\begin{tabular}{|c|c|c|c|c|c|}
\hline Stage & Starting time & $\begin{array}{c}\text { Mean rate } \\
\left(\mathrm{mm} \mathrm{month}^{-1}\right)\end{array}$ & $\begin{array}{c}\text { Rate mad } \\
\left(\mathrm{mm} \mathrm{month} \mathrm{mon}^{-1}\right)\end{array}$ & $\begin{array}{l}\text { Rainy day } \\
\text { frequency }\end{array}$ & $\begin{array}{l}\text { Duration } \\
\text { (yr) }\end{array}$ \\
\hline S1 & & 49 & 17 & 0.50 & \\
\hline $\mathrm{S} 2$ & 2008 May & 83 & 40 & 0.54 & 1.51 \\
\hline S3 & 2009 November-December & 164 & 43 & 0.57 & 2.80 \\
\hline S4 & 2012 September & 276 & 102 & 0.66 & 1.48 \\
\hline S5 & 2014 March & 52 & 33 & 0.55 & \\
\hline
\end{tabular}




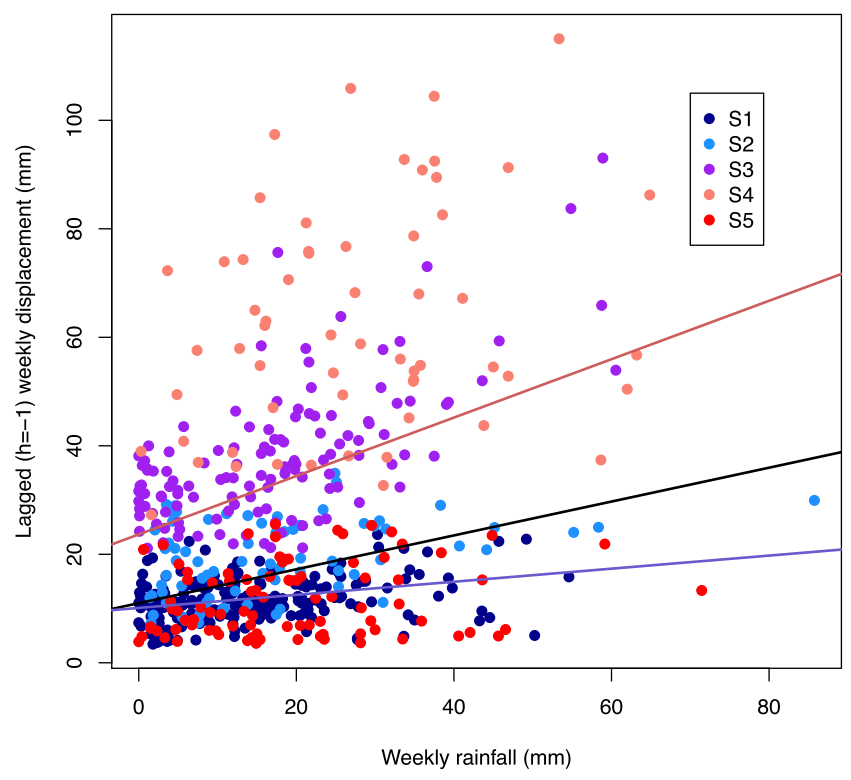

Figure 11. Lagged scatter plot of displacement rates and rainfall (weekly series) for each displacement stage (S1-S5). The lag is $h=-1$ (7 d). For S3-S5 stages, the fitting line (in red) is steeper than for S1-S2 stages (in blue). The black line is the regression line for all the points (S1-S5 stages).

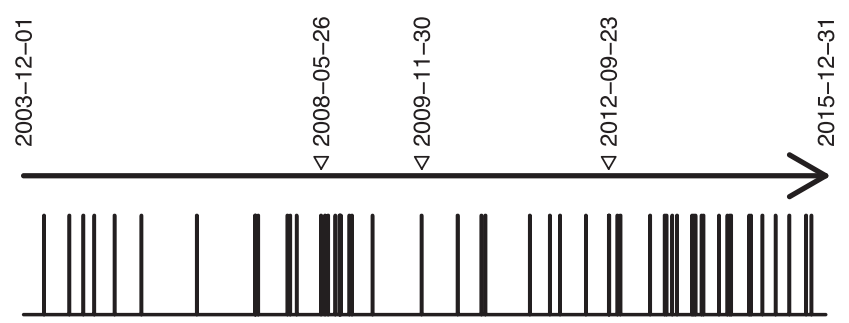

Figure 12. Graphical comparison of the starts of the displacement phases (top) and the heavy rainfall events (bottom). Above the time arrow, the starts of displacement phases S2, S3 and S4 are marked (dates and inverted triangles). Below the arrow, each vertical bar marks a day of heavy rainfall: we have chosen to define a day of heavy rainfall as a day when rainfall daily amounts are more than $17.6 \mathrm{~mm}$. This value is the 0.98 quantile of the distribution of the study rainfall data set. The coincidence of the starts of displacement phases with heavy rainfall events is unquestionable.

for studies of the kinematics of volcanic or seismic areas. When applied to the Séchilienne rock avalanche, the RSMCPM identifies and quantifies five kinematic stages in the 2003-2015 period with the following features:

(i) during these stages, the displacement rate values correlate both with rainfall rate value and the rainy day frequency (Fig. 10). The observed relationships allow us to suggest that the frequency of rainy days is a key parameter that controls the displacement rates, more clearly than the rainfall amount does;

(ii) the durations of stages are longer than $1.5 \mathrm{yr}$, in accordance with the strong inertia of the rockslide displacement;

(iii) the onsets of stages (accelerating step) always coincide with heavy rainfall episodes;

(iv) the interrelationship between displacement and rainfall rates evolves over stages and time (Fig. 11). Accordingly, we suggest that the beginning of 2010 marks a crucial moment in the acceleration of the kinematics of the Séchilienne rock avalanche; (v) in 2014 March (onset of the last stage), the possible fracture opening within the rockslide and the resulting fall in pore pressure slows the rockslide back to displacement rates of 2003.

\section{ACKNOWLEDGEMENTS}

We acknowledge OMIV, the CEREMA (Centre d'Etudes et d'Expertise sur les Risques, l'Environnement, la Mobilité et l'Aménagement) of Lyon and Sébastien Pierart (ROMMA association) for providing displacement and meteorological data (thanks to CEREMA to make the data available through the SNO-INSU OMIV portal: https://omiv.osug.fr/data.html). Graphics were performed using $\mathrm{R}$ (3.3.2) version statistical programming environment (R Core Team 2014) available from http://www.r-project.org/ under the General Public License. Rank sum change-point analyses were performed using the R library ACA that is available also from http://www.r-project.org/ under the General Public License. Many thanks are due to anonymous reviewers for their constructive comments on the original manuscript.

\section{REFERENCES}

Abellán, A., Michoud, C., Jaboyedoff, M., Baillifard, F., Demierre, J., Carrea, D. \& Derron, M.-H., 2015. Velocity prediction on time-variant landslides using moving response functions: application to la barmasse rockslide (Valais, Switzerland), in Engineering Geology for Society and TerritoryVolume 2, pp. 323-327, Springer.

Amorèse, D., 2007. Applying a change-point detection method on frequency-magnitude distributions, Bull. seism. Soc. Am., 97(5), 17421749.

Barry, D. \& Hartigan, J.A., 1993. A bayesian analysis for change point problems, J. Am. Stat. Assoc., 88(421), 309-319.

Baum, R.L. \& Godt, J.W., 2010. Early warning of rainfall-induced shallow landslides and debris flows in the usa, Landslides, 7(3), 259-272.

Benoit, L., Briole, P., Martin, O., Thom, C., Malet, J.-P. \& Ulrich, P., 2015. Monitoring landslide displacements with the geocube wireless network of low-cost gps, Eng. Geol., 195, 111-121.

Bernardie, S., Desramaut, N., Malet, J.-P., Gourlay, M. \& Grandjean, G., 2015. Prediction of changes in landslide rates induced by rainfall, Landslides, 12(3), 481-494.

Bogaard, T. \& Greco, R., 2017. Invited perspectives. a hydrological look to precipitation intensity duration thresholds for landslide initiation: proposing hydro-meteorological thresholds, in Natural Hazards and Earth System Sciences Discussions, pp. 1-17, doi:10.5194/nhess-2017-241.

Bradley, R.S., Hughes, M.K. \& Diaz, H.F., 2003. Climate in medieval time, Science, 302(5644), 404-405.

Brocca, L., Ponziani, F., Moramarco, T., Melone, F., Berni, N. \& Wagner, W., 2012. Improving landslide forecasting using ascat-derived soil moisture data: a case study of the torgiovannetto landslide in central italy, Remote Sens., 4(5), 1232-1244.

Brocca, L., Ciabatta, L., Moramarco, T., Ponziani, F., Berni, N. \& Wagner, W., 2016. Use of Satellite Soil Moisture Products for the Operational Mitigation of Landslides rRisk in Central Italy. Elsevier, Amsterdam, The Netherlands.

Cappa, F., Guglielmi, Y., Viseur, S. \& Garambois, S., 2014. Deep fluids can facilitate rupture of slow-moving giant landslides as a result of stress transfer and frictional weakening, Geophys. Res. Lett., 41(1), 61-66.

Chanut, M.-A., Vallet, A., Dubois, L. \& Duranthon, J.-P., 2013. Mouvement de versant de séchilienne: relations entre déplacements de surface et apports hydriques-analyse statistique, Séchilienne unstable slope: relationships between surface velocities and water input-statistical approach, in 3ème Journée des Aléas Gravitaires (JAG 2013), pp. 1-6, Grenoble, France. 
Confuorto, P. et al., 2017. Post-failure evolution analysis of a rainfalltriggered landslide by multi-temporal interferometry sar approaches integrated with geotechnical analysis, Remote Sens. Environ., 188, 51-72.

Crosta, G. \& Agliardi, F., 2003. Failure forecast for large rock slides by surface displacement measurements, Can. Geotech. J., 40(1), 176-191.

Crosta, G., Di Prisco, C., Frattini, P., Frigerio, G., Castellanza, R. \& Agliardi, F., 2014. Chasing a complete understanding of the triggering mechanisms of a large rapidly evolving rockslide, Landslides, 11(5), 747-764.

Durville, J., Kasperki, J. \& Duranthon, J., 2009. The séchilienne landslide: monitoring and kinematics, in Proceedings of First Italian Workshop on Landslides, Vol. 1, Naples, pp. 174-180, eds Picarrelli, L., Tommasi, P., Urciuoli, G. \& Versace, P.

Erdman, C. \& Emerson, J.W., 2007. bcp: an R package for performing a bayesian analysis of change point problems, J. Stat. Softw., 23(3), 1-13.

Federico, A., Popescu, M., Fidelibus, C. \& Interno, G., 2004. On the prediction of the time of occurrence of a slope failure: a review, in Landslide: Evaluation and Stabilization, Proceedings of the 9th International Symposium on Landslides, Rio de Janeiro, pp. 979-1188, eds Lacerda, W.A., Ehrlich, M., Fontoura, S.A.B. \& Sayao, A.S.F., A. A. Balkema, Leiden.

Fisher, R.A., 1925. Statistical Methods for Research Workers, Genesis Publishing Pvt Ltd.

Garambois, S., 2014. Compte-rendu de fin de projet ANR-09RISK-008 SLAMS. Available at: http://risknat.org/wp-content/uploads/ 2015/12/SLAMS-Rapport-scientifique-combine-final2.pdf, last accessed 24 July 2016.

Godt, J.W., Baum, R.L. \& Chleborad, A.F., 2006. Rainfall characteristics for shallow landsliding in Seattle, Washington, USA, Earth Surf. Process. Landf., 31(1), 97-110.

Greco, R. \& Bogaard, T., 2016. The influence of non-linear hydraulic behavior of slope soil covers on rainfall intensity-duration thresholds, in $12 \mathrm{th}$ International Symposium on Landslides, pp. 1021-1025, CRC Press.

Helmstetter, A. \& Garambois, S., 2010. Seismic monitoring of séchilienne rockslide (french alps): analysis of seismic signals and their correlation with rainfalls, J. geophys. Res., 115(F3), doi:10.1029/2009JF001532

Hollander, M. \& Wolfe, D.A., 1973. Nonparametric Statistical Methods, Wiley, New York.

Horváth, L. \& Rice, G., 2014. Extensions of some classical methods in change point analysis, Test, 23(2), 219-255.

Hufschmidt, G. \& Crozier, M.J., 2008. Evolution of natural risk: analysing changing landslide hazard in wellington, aotearoa/new zealand, Nat. Hazards, 45(2), 255-276.

Hungr, O., Corominas, J. \& Eberhardt, E., 2005. Estimating landslide motion mechanism, travel distance and velocity, Landslide Risk Manage., 1, 99128.

James, N.A. \& Matteson, D.S., 2014. ecp: an R package for nonparametric multiple change point analysis of multivariate data, J. Stat. Softw., 62(7), $1-25$.

Jones, P.D. \& Mann, M.E., 2004. Climate over past millennia, Rev. Geophys., 42(2), 1-42.

Kasperski, J., Delacourt, C., Allemand, P., Potherat, P., Jaud, M. \& Varrel, E., 2010. Application of a terrestrial laser scanner (tls) to the study of the séchilienne landslide (isère, france), Remote Sens., 2(12), 2785-2802.

Killick, R., Eckley, I.A., Ewans, K. \& Jonathan, P., 2010. Detection of changes in variance of oceanographic time-series using changepoint analysis, Ocean Eng., 37(13), 1120-1126.

Klein, E., Durenne, A. \& Gueniffey, Y., 2013. L'analyse statistique de données appliquée à la surveillance multi-paramètres de versants instables, in Journées Aléa Gravitaire (JAG), Grenoble, France.

Lanzante, J.R., 1996. Resistant, robust and non-parametric techniques for the analysis of climate data: theory and examples, including applications to historical radiosonde station data, Int. J. Climatol., 16(11), 1197-1226.

Lanzante, J.R., Klein, S.A. \& Seidel, D.J., 2003. Temporal homogenization of monthly radiosonde temperature data. Part I: methodology, J. Climate, 16(2), 224-240.

Mann, H.B. \& Whitney, D.R., 1947. On a test of whether one of two random variables is stochastically larger than the other, Ann. Math. Stat., 18(1) $50-60$.
Matyasovszky, I., 2011. Detecting abrupt climate changes on different time scales, Theor. Appl. Climatol., 105(3-4), 445-454.

Perreault, L., Parent, E., Bernier, J., Bobee, B. \& Slivitzky, M., 2000. Retrospective multivariate bayesian change-point analysis: a simultaneous single change in the mean of several hydrological sequences, Stoch. Environ. Res. Risk Assess., 14(4-5), 243-261.

Piao, S., Yin, L., Wang, X., Ciais, P., Peng, S., Shen, Z. \& Seneviratne, S.I., 2009. Summer soil moisture regulated by precipitation frequency in china, Environ. Res. Lett., 4(4), 044012, doi:10.1088/1748-9326/4/4/044012.

Ponziani, F., Pandolfo, C., Stelluti, M., Berni, N., Brocca, L. \& Moramarco, T., 2012. Assessment of rainfall thresholds and soil moisture modeling for operational hydrogeological risk prevention in the umbria region (central italy), Landslides, 9(2), 229-237.

R Core Team, 2014. R: A Language and Environment for Statistical Computing, $R$ Foundation for Statistical Computing, Vienna, Austria.

Ray, R.L. \& Jacobs, J.M., 2007. Relationships among remotely sensed soil moisture, precipitation and landslide events, Nat. Hazards, 43(2), 211222.

Rianna, G., Zollo, A., Tommasi, P., Paciucci, M., Comegna, L. \& Mercogliano, P., 2014. Evaluation of the effects of climate changes on landslide activity of orvieto clayey slope, Proc. Earth Planet. Sci., 9, $54-63$.

Salmon, M., Schumacher, D. \& Höhle, M., 2014. Monitoring count time series in $R$ : aberration detection in public health surveillance, doi:1411.1292.

Schlögel, R., Doubre, C., Malet, J.-P. \& Masson, F., 2015. Landslide deformation monitoring with alos/palsar imagery: a d-insar geomorphological interpretation method, Geomorphology, 231, 314-330.

Shapiro, S.S. \& Wilk, M.B., 1965. An analysis of variance test for normality (complete samples), Biometrika, 52(3/4), 591-611.

Siegel, S. \& Castellan Jr, N.J., 1988. Nonparametric Statistics for the Behavioral Sciences, McGraw-Hill, New York.

Siegmund, J.F., Siegmund, N. \& Donner, R.V., 2017. Coincalc-a new r package for quantifying simultaneities of event series, Comput. Geosci., 98, 64-72.

Tatard, L., Grasso, J., Helmstetter, A. \& Garambois, S., 2010. Characterization and comparison of landslide triggering in different tectonic and climatic settings, J. geophys. Res., 115(F4), doi:10.1029/2009JF001624.

Touati, S., Naylor, M. \& Main, I., 2016. Detection of change points in underlying earthquake rates, with application to global mega-earthquakes, Geophys. J. Int., 204(2), 753-767.

Tukey, J.W., 1960. A survey of sampling from contaminated distributions, Contrib. Probab. Stat., 2, 448-485.

Vallet, A., Bertrand, C. \& Mudry, J., 2013. Effective rainfall: a significant parameter to improve understanding of deep-seated rainfall triggering landslide-a simple computation temperature based method applied to séchilienne unstable slope (french alps), Hydrol. Earth Syst. Sci. Discus., 10(7), 8945-8991.

Van Asch, T.W., Buma, J. \& Van Beek, L., 1999. A view on some hydrological triggering systems in landslides, Geomorphology, 30(1), 25-32.

Wald, A. \& Wolfowitz, J., 1943. An exact test for randomness in the nonparametric case based on serial correlation, Ann. Math. Stat., 14(4), 378388 .

Wilcoxon, F., 1945. Individual comparisons by ranking methods, Biometrics Bull., pp. 80-83.

Wu, C. et al., 2012. An underestimated role of precipitation frequency in regulating summer soil moisture, Environ. Res. Lett., 7(2), 024011, doi:10.1088/1748-9326/7/2/024011.

Yamanishi, K., Takeuchi, J.-I., Williams, G. \& Milne, P., 2000. On-line unsupervised outlier detection using finite mixtures with discounting learning algorithms, in Proceedings of the Sixth ACM SIGKDD International Conference on Knowledge Discovery and Data Mining, pp. 320-324, ACM.

Yan, H., Soon, W. \& Wang, Y., 2015. A composite sea surface temperature record of the northern south china sea for the past 2500 years: a unique look into seasonality and seasonal climate changes during warm and cold periods, Earth Sci. Rev., 141, 122-135. 